\title{
GLOBALISASI DAN MASA DEPAN FIKIH (KAJIAN SHIGAT AQAD NIKAH)
}

Eka Suriansyah

IAIN Palngka Raya, Palangka Raya, Indonesia

ekasuriansyah@gmail.com

Received:31-11-2018; Revised:15-12-2018; Accepted: 17-12-2018

ABSTRACT

The development of a significant Islamic economy in Indonesia, demands a set of legislations that can provide legal certainty to practitioners of Islamic economics in carrying out sharia economics. The existence of sharia economic regulation in the Indonesian legal system is colored by legal dynamics. This study examines the background of structuring the regulation of Islamic economics in Indonesia, and the dynamics of structuring the regulation of Islamic economics in Indonesia. The method used in this study uses normative legal research with statute approach, historical approach and conceptual approach that is analyzed qualitatively. The results of this study indicate that the needs of the Islamic community in carrying out the part of Islamic Shari'a in the context of Islamic economics muamalah, require compulsory legal certainty in order to provide assurance and assurance of compliance and fulfillment of sharia compliance that must be fulfilled by the state through regulation. The dynamics of structuring sharia economic regulation in Indonesia can be seen in the form of closed systems and open systems, both from operational regulations, institutions and dispute resolution. The dynamics of structuring Islamic economic regulation in a closed system refers to the legal hierarchy and legal system through legal politics that undergo a long process from 1992 to 2018. While in an open system, the dynamics of regulation of sharia economic regulation develops rapidly, responsively and progressively through jurisprudence decisions court and MUI DSN fatwa.

Key Words: Globalization, Fiqh, SHigat

\section{ABSTRAK}

Majunya dunia teknologi pada dasawarsa millennial, melahirkan sebuah era baru yang disebut globalisasi. Ia lahir sebagai klimak dari modernisasi dunia Barat yang membawa perubahan terhadap pola interaksi dan komunikasi dunia. Implikasinya adalah perubahan terminologi ruang dan waktu hinggakehadirannya memangkas batas keduanya. Kondisi ini membawa dampak sistemik dalam berbagai segment dan piranti sosial. Keadaan masyarakat di era ini sudah bergeser dari terminologi tradisional tentang ruang dan waktu, menuju terminologi global. Konsep keduanya dalam terminologi globalisasi bersifat virtual; bertemu dalam waktu yang sama namun dalam dimensi ruang yang berbeda. Kondisi ini membentuk pola dan cara pandang baru terhadap dimensi ruang dan waktu. Dalam kajian fikih, interpretasi terhadap makna ruang dan waktu adalah suatu yang urgen. Ia akan sangat besar memberikan implikasi pada produk hukum. Terlebih kehadiran kitab-kitab fikih berada pada era klasik. Seperti shigat ijab-qabul dalam prosesi pernikahan yang mensyaratkan bersatunya dalam satu ruang mengharuskan lahirnya pemahaman baru terhadap kata ruang. Kata ruang dalam interpretasi era pra-globalisasi adalah ruang dalam arti yang sesungguhnya, berada dalam rentang waktu dan tempat yang sama, sedang ruang dalam era globalisasi bisa diterjemahkan sebagai ruang dalam 
arti sesungguhnya, dan bisa pula ruang dalam arti hanya bersatunya dalam satu waktu namun berada dalam tempat yang berbeda

Kata Kunci:Globalisasi, Fikih, Shigat.

\section{A. Pendahuluan}

Majunya dunia tehnologi pada dasawarsa ini, melahirkan sebuah era baru yang disebut dengan era globalisasi. Era globalisasi lahir sebagai klimak dari modernisasi di belahan dunia Barat, dengan ditandai pengintegrasian ekonomi, budaya, dan ideologi secara global. ${ }^{1}$ Kelahiran makhluk baru ini membawa perubahan besar terhadap pola interaksi dan komunikasi dunia saat ini. Istilah globalisasi pertama kalinya digunakan sebagai kata benda dalam sebuah tulisan berjudul Towards New Education. Kata globalisasi di sini menunjukkan pandangan pengalaman manusia secara menyeluruh di bidang pendidikan. ${ }^{2}$ Istilah serupa yang dicetuskan oleh Charles Taze pada tahun 1897 dengan corporate giants (raksasa perusahaan), untuk menyebut perusahaan-perusahaan besar nasional pada waktu itu. Tahun 1960an, kedua istilah tadi mulai dijadikan sinonim oleh para ekonom dan ilmuwan sosial lainnya. Ekonom Theodore Levitt diakui secara luas sebagai pencipta istilah kata globalisasi melalui artikelnya yang berjudul Globalization of Markets. Artikel ini terbit di Harvard Business Review edisi Mei-Juni 1983. Namun, kata globalisasi sebelumnya sudah banyak digunakan setidaknya sejak 1944 dan dipakai oleh beberapa pengamat sejak 1981. Dan orang yang dianggap mempopulerkan kata ini dan memperkenalkannya kekalangan pebisnis utama pada paruh akhir 1980an adalah Levitt.

Banyak pakar mendefinisikan globalisasi, diantaranya Roland Robertson ${ }^{3}$ yang mendefinisikannya pada tahun 1992 sebagai pemadatan dunia dan pemerkayaan kesadaran dunia secara keseluruhan (baca:global). ${ }^{4}$ Sosiolog Martin Albrow dan Elizabeth King mendefinisikan globalisasi sebagai semua proses yang menyatukan penduduk dunia menjadi satu masyarakat dunia yang tunggal. Dalam buku The Consequences of Modernity, Anthony Giddens mengartikan globalisasi sebagai intensifikasi hubungan sosial dunia yang menghubungkan tempat-tempat jauh sehingga peristiwa di suatu tempat dapat dipengaruhi oleh peristiwa yang terjadi di tempat lain.

David Held dalam bukunya Global Transformations mendefinisikan globalisasi dalam artian paling sederhananya globalisasi mengacu pada pelebaran, pendalaman, dan pemercepatan interkoneksi global. Ia dapat merujuk pada proses perubahan ruang-waktu yang menopang transformasi susunan kehidupan manusia dengan menghubungkan sekaligus memperluas aktivitas manusia melintasi wilayah dan benua tanpa melihat kaitan keruangan. ${ }^{5}$

Dalam buku The Race to the Top: The Real Story of Globalization, jurnalis Swedia Thomas Larsson menyatakan bahwa globalisasi adalah proses penyusutan dunia sehingga jarak semakin pendek dan segala hal terasa semakin dekat. Globalisasi mengacu pada semakin mudahnya interaksi antara seseorang di satu tempat dengan orang lain di belahan dunia yang lain. Jurnalis Thomas L. Friedman mempolerkan kata flat world (dunia datar) dalam mengistilahkan globalisasi. Ia berpendapat bahwa perdagangan global, outsourcing, rantai suplai,

\footnotetext{
${ }^{1}$ Proses terbentuk globalisasi lihat di Dari Pembangunan Ke Globalisasi dalam Mansour Fakih, Runtuhnya Teori Pembangunan dan Globalisasi (Yogyakarta: Pustaka Pelajar, 2006), hlm. 208

${ }^{2} \mathrm{http}$ ://id.wikipedia.org/wiki/Globalisasi diakses 12November 2018

${ }^{3}$ Ia adalah salah satu penulis pertama di bidang globalisasi

${ }^{4}$ Lih. Roland Robertson, Globalization : social theory and global culture, (London: Sage, 1992)

${ }^{5}$ Definisi ini dapat dibandingkan dalam A. Qadri Azizy, Melawan Globalisasi Ajaran Islam; Reinterpretasi Ajaran Islam (Yogyakarta: Pustaka Pelajar, 2004), hlm. 8 dan 18
} 
dan kekuatan politik telah mengubah dunia lebih baik atau buruk secara permanen. Ia menegaskan bahwa globalisasi berlangsung semakin cepat dan pengaruhnya terhadap organisasi dan praktik bisnis akan terus berkembang. ${ }^{6}$

Dari beberapa paparan definisi tersebut dapat ditarik benang merah tentang ciri-ciri globalisasi. Globalisasi membawa perubahan dalam konsep ruang dan waktu. Terjadinya peningkatan interaksi kultural melalui perkembangan media massa. Meningkatnya masalah bersama seperti di bidang lingkungan hidup, krisis multinasional, inflasi regional dan lain sebagainya. Ciri-ciri lainnya kebijakan-kebijakan nasional (seperti dalam bidang-bidang sosial budaya, ekonomi,dan teknologi) yang sekarang berada dalam yurisdiksi suatu pemerintahan dan masyarakat dalam suatu wilayah bergeser menjadi di bawah pengaruh atau di proses badanbadan internasional atau perusahaan besar serta pelaku ekonomi keuangan internasional. Dan ciri-cirinya secara umum yaitu meningkat bahkan berkembangnya berbagai teknologi informasi dan komunikasi yang memudahkan manusia berinteraksi tanpa bertatapan wajah dan memudahkan mendapatkan informasi dari negara atau daerah lain tanpa perlu datang ke negara atau daerah tersebut. Terjadinya perubahan cara berfikir orang-orang dan berorientasi pada masa depan.

\section{B. Metode Penelitian}

Metode pendekatan yang digunakan berupa yuridis normatif. Pendekatan yuridis normatif yaitu penelitian yang berdasarkan pada kaidah-kaidah hukum yang ada untuk melihat kenyataankenyataan yang terjadi. Jenis data yang digunakan adalah data sekunder. Pengumpulan data dilakukan dengan cara penelitian kepustakaan, yaitu mempelajari buku-buku, makalah, literatur, jurnal artikel serta peraturan perundang-undangan yang berkaitan dengan obyek penelitian dan menghubungkannya dengan keadaan sosial yang terjadi di masyarakat.

\section{Pembahasan}

\section{Pergeseran Terminologi Ruang dan Waktu Pengaruh Globalisasi}

Globalisasi yang hadir sekarang dengan perlahan tapi pasti memangkas batas ruang dan waktu. Menurut Marshall McLuhan dunia sekarang tidak lebih dari sebuah desa. ${ }^{7}$ Kondisi seperti ini membawa dampak sistemik dalam berbagai segment dan piranti sosial. Keadaan masyarakat sudah bergeser dari terminologi tradisional tentang ruang dan waktu, menuju konsep ruang dan waktu dalam terminologi global. Konsep ruang dan waktu dalam terminologi globalisasi bersifat virtual; bertemu dalam waktu yang sama namun dalam dimensi ruang yang berbeda. Media komunikasi, bahkan ilmu pengetahuan kita pun sudah tidak terbatas dalam ruang dan waktu. Kondisi masyarakat serta ilmu pengetahuan seperti ini disebut Manuel Castells sebagai "masyarakat jaringan". ${ }^{8}$

Kelahiran globalisasi pada milenium III, yang berbeda dari era sebelumnya membentuk pola dan cara pandang baru. Ranah fikih sebagai produk pemikiran manusia dalam menerjemahkan syariat lahir dalam era klasik. Di mana dimensi ruang dan waktu masih dalam terminologi pra-modern. Tidak mengherankan kitab-kitab fikih yang lahir pada abad VIII hingga sekarang masih bernuansa terminologi ruang dan waktu di masa ia dilahirkan. Pemaknaan kasuskasus fikih masih bersifat regional.

\footnotetext{
${ }^{6}$ Lih.http://id.wikipedia.org/wiki/Globalisasi diakses 12November 2018

${ }^{7}$ Rob Shields, The Virtual, terj. Hera Oktaviani (Yogyakarta: Jalasutra, 2011), hlm 88

${ }^{8}$ Pip Jones, Pengantar Teori-teori Sosial, terj. Achmad Fedyani Saifuddin (Jakarta: Yayasan Obor Indonesia, 2010), hlm. 220
} 
Pergeseran terminologi fikih klasik terhadap ruang dan waktu ini dapat dilihat diantaranya pada kasus nikah via telphon pada tahun 1989 di Jakarta. Pernikahan dilakukan menggunakan media telephon -media tercanggih produk era globalisasi di tahun itu- yang menghubungkan mempelai pria berada di Amerika Serikat dengan wali nikah di Jakarta. Ketika pernikahan itu terjadi gelombang perdebatan ulama fikih serta cendekiawan muslim yang terjadi di era 90-an terjebak pada sah atau tidaknya peristiwa hukum tersebut. Masing-masing kubu mencoba mengemukakan argumentasi berpijak pada berbagai dalil yang ada dalam kitab fikih dengan cara interpretasinya masing-masing. Meminjam istilah Abd al-majid Shubuh, ${ }^{9}$ diskursus wacana terjadi antara ashhabul lafz dan ashhab al-ma'na. Mereka seolah-olah dikagetkan oleh fenomena 'mukjizat modern' yang merangkak masuk ke ranah sakralitas fikih.

Kondisi sosio-kultural antara Indonesia dan Amerika saat peristiwa hukum terjadi sangat berbeda. Telepon di dunia Barat pada tahun 1998 sudah menjadi alat komunikasi utama di masyarakat. Bahkan terdapat 1 juta masyarakat Amerika pengguna telepon seluler (hand phone) di tahun $1998 .{ }^{10}$ Sedang di Indonesia pada tahun yang sama telepon masih terbatas pada instansi publik seperti perkantoran atau perusahaan, masih belum menjadi alat komunikasi yang umum digunakan masyarakat diberbagai lapisan. Untuk kelas menengah dan bawah di tahun itu masih tergantung pada penyedia jasa layanan umum telepon; wartel. Begitu pula tekhnologi nirkabel seperti internet, terjadi perbedaan yang sangat signifikan antara Indonesia dan Amerika di tahun itu. Di Amerika tahun 1981 email (electronic mail) sudah menjadi alat untuk komunikasi jarak jauh, dan di tahun 1994 situs internet berbasiskan domain www sudah di mulai. Keadaan yang jauh berbeda dengan Indonesia yang baru memulai menggunakan internet pada tahun 1995 . $^{11}$ Sebagai perbandingan di Amerika pada tahun 2000 sejumlah 43.1\% penduduknya menggunakan internet $^{12}$ sedang di Indonesia di tahun yang sama $1.9 \%$ dari penduduknya yang menggunakan internet. ${ }^{13}$ Dan sejatinya internet masuk ke Indonesia pada tahun 1989.

Perbedaan kultur memberikan indikasi yang kuat dalam ranah hukum Islam. Kultur yang membentuk pola pikir masyarakatnya, begitu pula nalar hukum Islam sangat besar dipengaruhi oleh kultur yang terbentuk di masa lahirnya hukum Islam. Jadi, sangat wajar di tahun 1989 permasalahan nikah via telepon direspon secara pesimis dengan berpegang dengan dalil-dalil yang bersifat tekstualis dan dalam terminologi ruang dan waktu klasik.

\section{Sighat dalam Fikih Nikah}

Fitrah manusia dilengkapi Tuhan dengan kecenderungan seks (libido seksual). Sudah menjadi kodrat alam, bahwa dua orang manusia dengan jenis kelamin yang berbeda, seorang perempuan dan laki-laki ada daya tarik satu sama lainnya untuk hidup bersama. Karena Islam adalah agama yang fitrah, maka menyediakan wadah yang legal untuk terselenggaranya penyaluran tersebut yang sesuai dengan derajat manusia. ${ }^{14}$ Pernikahan merupakan suatu yang lumrah dan merupakan fitrah manusia normal dalam melanjutkan regenerasi kehidupan manusia.

\footnotetext{
${ }^{9}$ Abd al-Madjid Shubh, Ushul al-Manahij al-Fiqhiyyat (Kairo: Dar al-Wafa, 1989), hlm. 63

${ }^{10}$ Assa Briggs dan Peter Burke, Sejarah Sosial Media dari Gutenberg sampai Internet, Penerjemah. A. Rahman Zainuddin (Jakarta: yayasan Obor, 2006), hlm. 373

${ }^{11}$ Baca sejarah internet masuk ke Indonesia http://adeannatha.blogspot.com/ akses pada 12November 2018 atau lihat David T. Hill dan Krishna Sen, The Internet in Indonesia's New Democracy (new York: Routledge, 2005), hal. 56

${ }_{12}$ Data pengguna internet di Amerika dapat di lihat https://www.census.gov/prod/2001pubs/p23-207.pdf atau https://en.wikipedia.org/wiki/Internet_in_the_United_States

${ }^{13}$ Data pengguna internet di Indonesia dapat diakses https://nandonurhadi.wordpress.com/2013/02/20/jumlahpengguna-internet-indonesia-tahun-1998-2012-versi-apjii/

${ }^{14}$ Agus Hermanto, Larangan Perkawinan, (Yogyakarta: Lintang rasi Aksara Books, 2016), hlm. 1
} 
Pernikahan bukanlah suatu aib dan bukan pula suatu kekurangan. ${ }^{15}$ Namun pernikahan merupakan sesuatu yang mulia dan sempurna. Melalui pernikahan, Allah menjadikannya sebagi cara untuk melestarikan keturunan manusia yang sesuai fitrahnya.

Menikah merupakan suatu ibadah di dalam Islam. Ia bukan hanya sebuah perayaan seremonial formalitas yang tidak ada implikasi jangka panjang. Namun ada aturan-aturan yang harus dipenuhi agar bisa disebut sebuah pernikahan dalam Islam. Sebagaimana jamak-nya ibadah dalam Islam yang diliputi syarat dan rukun sebagai prasyarat disebutnya sebuah ritual atau perilaku tertentu sebagai ibadah. Begitu pula pernikahan ada beberapa syarat dan rukun yang harus dipenuhi agar pernikahan tersebut legal secara Islam.

Syarat sah nikah adalah syarat-syarat yang menjadi tolak ukur keabsahan suatu pernikahan. Jika terpenuhi, berarti akad pernikahan tersebut dianggap berlaku sesuai syariat dan berlakulah semua hukum dan hak yang menjadi konsekwensinya. Syarat-syarat tersebut terbagi menjadi dua, status mempelai wanita adalah halal bagi laki-laki yang hendak mempersuntingnya merupakan syarat pertama. Artinya, wanita tersebut disyaratkan bukan mahram laki-laki tersebut berdasarkan sebab apapun yang membuatnya menjadi mahram, baik mahram sementara atau maupun abadi. ${ }^{16}$ Sedang syarat kedua adalah penyaksian pernikahan. Jumhur Ulama berpendapat suatu pernikahan tidak sah kecuali ada bukti. Juga tidak sah kecuali saksi-saksi hadir saat akad nikah dilangsungkan sekalipun dapat diumumkan secara terbuka dengan sarana lain. Ini berarti apabila para saksi hadir dan kedua belah pihak yang melangsungkan akad berpesan agar mereka menyimpan berita akad tersebut dan tidak menyebarkannya, maka akad tetap sah. ${ }^{17}$

Rukun terjadinya pernikahan ada lima menurut Madzhab Syafi'i, yaitu calon suami, calon isteri, dua orang saksi, wali dan shigat. ${ }^{18}$ Sedang menurut pendapat Hanafiah rukun nikah hanya mencakup ijab dan qabul. ${ }^{19}$ Memiliki kesaman dengan madzhab Syafi'i, Madzhab Maliki menetapkan rukun nikah itu ada lima, yaitu shigat, colan suami dan istri, wali, dua orang saksi dan mahar. Ia menggabungkan calon suami dan istri menjadi satu rukun dan menambahkan mahar sebagai rukun yang kelima. Menurut Sayyid Sabiq rukun nikah yang sebenarnya adalah adanya keridhaan dari kedua belah pihak dan kemauan bersama untuk menjalin hubungan. ${ }^{20}$

Keridhaan dan kemauan bersama bagian dari perasaan hati yang tidak kasatmata, maka harus ada ungkapan yang menunjukkan tekad membangun dan menciptakan jalinan hubungan. Ungkapan tersebut terejawantahkan dalam redaksi yang diucapkan oleh dua belah pihak yang melakukan akad. Redaksi yang diucapkan lebih dulu untuk mengungkapkan kemauan menjalin hubungan suami-istri disebut ijab. Sehingga yang mengucapkannya disebut telah melakukan ijab. Sedangkan redaksi kedua yang diucapkan oleh orang yang melakukan akad untuk menunjukkan penerimaan dan persetujuan disebut qabul. Redaksi ijab dan qabul ini disebut shigat dan para ulama fiqih menyebutkan bahwa rukun nikah adalah ijab dan qabul.

Untuk sahnya ijab dan qabul harus memenuhi syaratnya yang sudah ditentukan oleh ulama fikih. Syarat pertama sahnya ijab dan qabul adalah tamyiz (mampu membedakan baik dan

\footnotetext{
${ }^{15}$ Yusuf Amru, Istri-Istri Rasulullah, Contoh dan Teladan, (Jakarta: Gema Insani Press, 1997), hlm. 77

${ }^{16}$ Sayid Sabiq, Fiqhus Sunnah, (Beirut: Darul Fikri, 1983), VI:48

${ }^{17}$ Ibid., hlm. 49

18 Sebagian referensi menyebutkan empat dengan menjadikan calon suami dan isteri menjadi satu rukun. Ibnu Muhammad Syatha, I'anah Thalibin (Beirut: dar Fikri, t.th), III:316

${ }^{19}$ Wahbah Al Zuhaili, Fiqh al-Islami wa Adilatuh (Beirut: Dar Fikri, 1985), VII:36

${ }^{20}$ Sayid Sabiq, Fiqhus ..., hlm. 29
} 
buruk). Kedua orang yang akan melakukan aqad harus mumayyiz. ${ }^{21}$ Artinya kalau salah satunya gila atau terlalu kecil sehingga belum mampu membedakan baik dan buruk maka akad nikah tidak sah. $^{22}$

Syarat ijab dan qabul yang kedua adalah berada dalam satu tempat (baca: majlis). Terjadinya ijab dan qabul harus dalam satu tempat, jika ijab belum diucapkan dan keduanya terpisah tempatnya, maka tidaklah sah aqad tersebut. ${ }^{23} \mathrm{Ijab}$ dan qabul tidak boleh disela oleh pembicaraan lain atau sesuatu yang menurut hukum kebiasaan dianggap menyimpang dan keluar dari permasalahan. Persyaratan yang ketiga adalah bersambungnya ijab dan qabul. Dan yang terakhir adalah qabul tidak menyimpang dari ijab, kecuali jika penyimpangan itu mengarah pada yang lebih baik dari yang disebutkan dalam ijab, sehingga menunjukkan persetujuan yang lebih kuat. Misalkan jika wali berkata, "aku nikahkan kamu dengan putraku yang bernama fulan, dengan mas kawin sebesar 100 pounds." Lalu dengan mas kawin 200 pounds." Maka akad seperti ini sah, karena qabulnya mencakup nilai yang lebih baik. ${ }^{24}$

Menjadi problem dalam terminologi fikih adalah disyaratkannya shigah akad nikah berada dalam satu majlis. Sayyid Sabiq menjelaskan maksud bersatunya majlis ijab dan qabul adalah tidak boleh disela oleh pembicaraan lain atau sesuatu yang menurut hukum kebiasaan dianggap menyimpang dan keluar dari permasalahan ijab dan qabul pernikahan. Wahbah Zuhaili menjadikan bersatunya ijab dan kabul dalam satu tempat berada diurutan pertama. ${ }^{25}$ Namun baginya bersatunya tempat apa bila kedua orang yang melakukan akad ijab dan qabul memang hadir, namun jika salah seorang tidak hadir dan hanya menitipkan surat yang ditulis didepan saksi maka dianggap sah pernikahan tersebut. ${ }^{26}$ Ia menegaskan yang dimaksud bersatunya tempat dalam pendapatnya adalah waktu akad bukan tempat orang yang berakad. Hal ini sesungguhnya untuk menepis anggapan bahwa bersatunya tempat adalah bersatunya tempat orang yang beraqad an sinch.

Pendefinisian ulang bersatunya ijab dan kabul bukan bersatunya tempat orang yang beraqad adalah terobosan baru dalam dunia fikih yang belum ditemukan dalam fikih sebelumnya. Melalui celah inilah -walau pendapat ini hanya didukung oleh madzhab Hanafiahdibolehkan shigat aqad via telephon atau video call. Dalam terminologi klasik bersatunya ijab dan qabul secara otomatis mengharuskan bersatunya orang yang beraqad dalam satu tempat, kondisi ini tidak bisa untuk kondisi sekarang. Kondisi saat ini dapat terjadi dua kemungkinan; kemungkinan pertama bersatunya ijab dan qabul dalam waktu dan ruang yang sama; dan kemungkinan kedua adalah bersatunya ijab dan qabul dalam waktu yang sama namun tidak bersau dalam ruang yang sama, seperti pertemuan virtual dalam video call.

Mengkaji lebih jauh fikih shighat ini, ada celah kedua yang memperkuat bahwa sejatinya pernikahan via telephone ataupun video call dibolehkan. Dalam prosesi akad nikah disyaratkan bagi yang beraqad mendengar perkataan yang satu dengan yang lainnya, serta para saksi mendengar pula apa yang mereka berdua katakan. ${ }^{27}$ Kondisi ini sudah terpenuhi dalam

\footnotetext{
${ }^{21}$ Mumayyiz adalah kondisi seorang dapat berkomunikasi dengan baik atau seorang mampu makan, minum, dan istinja sendiri tanpa bantuan orang lain dan kondisinya sehat. Lih. Abdullah al Harari, Umdatur Ragib, (t.tp: Darul Masyari', 2009), hlm. 134

${ }^{22}$ Ibid., hlm. 29

${ }^{23}$ Muhammad Abu Zahrah, Muhadharat fi 'aqdin nikah wa Atsaruh, (Kairo: darul Fikri Arabi, 1971), hlm. 77

${ }^{24}$ Sayid Sabiq, Fiqhus ..., hlm. 29

${ }^{25}$ Wahbah Al Zuhaili, Fiqh..., hlm. 49

${ }^{26}$ Ibid., hlm. 50

${ }^{27}$ Husain bin Muhammad, Al ifshah an aqdin nikah ala madzahibil arba'ah (Suria: Darul Qalam Arabi, 1995), hlm. 36
} 
percakapan via telephone ataupun video call. Terlebih prinsip dasar komunikasi di era sekarang adalah mendekatkan yang jauh hingga seolah tidak ada jarak antara keduanya. Bahkan dalam komunikasi yang terjadi dalam era digital ini, tidak hanya suara yang terdengar, bahkan wajah serta kondisi serta situasi satu sama lain dapat terlihat dengan jelas dan tergambar secara live dalam layar monitornya masing-masing.

\section{Arah Baru Terminologi Fikih Ruang dan Waktu}

Fikih virtual atau digital ${ }^{28}$ dalam era-globalisasi nampaknya memang menjadi keharusan zaman. Istilah fikih virtual atau digital memang belum pernah digunakan oleh ulama atau cendekiawan muslim di berbagai referensi dalam berbagai pembahasannya. Realitas yang dihadapi saat ini adalah realitas virtual dan digital. Realitas inilah yang membentuk dunia dan keseluruhan aktifitas manusia, mulai dari eksternalisasi, obyektivasi dan internalisasi (mengikuti konsep Peter L. Berger tentang dialektika manusia dan masyarakat) sebetulnya tak lain adalah aktifitas mendefinisikan dan membangun dunianya. ${ }^{29}$ Karena itu, masa depan agama akan sangat tergantung pada kemampuannya menyediakan definisi yang memuaskan bagi manusia atas segala sesuatu yang terjadi di dunia ini.

Fikih adalah produk pemikiran ulama dalam merespon realitas yang dihadapinya saat itu. Ia tak lain hanyalah produk pemikiran ulama yang lahir di era terminologi batas ruang dan waktu masih dalam terminologi klasik. Pada saat ditulis oleh para pengarangnya, kitab-kitab fikih tidak dimaksudkan untuk diberlakukan secara umum di suatu negeri, meskipun di dalam sejarah ditemukan beberapa buku fikih diberlakukan sebagai kitab undang-undang. ${ }^{30}$ Kitab-kitab fikih yang ada dan digunakan sekarang, saat ditulis oleh penulisnya tidaklah mempunyai masa kadaluarsa. Karena ia dikarang sebagai hasil dari respon realitas yang terjadi di saat itu. Sedang realitas sekarang adalah realitas virtual di jaman digitalisasi.

Dunia di era digitalisasi berupa dunia maya yang dapat mengambil alih realitas di dunia nyata, yang bagi banyak orang bahkan terasa lebih nyata dari kenyataan di dunia nyata, lebih menyenangkan dari kesenangan di dunia nyata, lebih fantastis dari semua fantasi yang pernah dirasakan manusia di dunia nyata, lebih menggairahkan dari semua kegairahan yang pernah ada. ${ }^{31}$ Kita tengah memasuki sebuah dunia baru, dunia maya, yang dapat dialami dalam tingkat pengalaman yang sama dengan dunia nyata. Apapun yang dapat kita lakukan di dunia nyata dapat juga kita lakukan di dunia maya, yang bisa jadi terasa lebih nyata dari kenyataan. Bahkan, apa yang di dunia nyata hanya berupa imajinasi, ilusi dan fantasi, di dunia cyber bisa diwujudkan dalam "realitas" dengan bantuan tekhnologi simulasi.

Era baru yang dihadapi sekarang membawa kepada sebuah realitas yang baru. Jadi, paradigma fikih haruslah disesuaikan dengan era baru tersebut. Tema sentral abad XX adalah modernisasi dan industrialisasi. Abad XXI temanya sudah bergeser pada teknologi informasi.

\footnotetext{
${ }^{28}$ Isitilah ini sengaja penulis gunakan untuk memberikan nama bentuk fikih yang dapat merespon perubahan jaman di era globalisasi 10 atau 20 bahkan 50 tahun kedepan.

${ }^{29}$ Eksternalisasi adalah suatu pencurahan kedirian manusia secara terus-menerus ke dalam dunia, baik dalam aktifitas fisik maupun mentalnya. Okyektivasi terjadi ketika produk dari aktifitas-aktifitas tersebut membentuk suatu fakta (faktisitas) yang bersifat eksternal. Kebudayaan adalah bentuk obyektivasi. Internalisasi adalah penerapan kembali realitas tersebut oleh manusia dan mentransformasikannya sekali lagi dari struktur-struktur dunia obyektif ke dalam struktur kesadaran subyektif. Peter L. Berger, Langit Suci, Agama sebagai Realitas Sosial (The Sacred Canopy: Elements of a Sociological Theory at Religion), Jakarta : LP3ES, 1991, hm. 4-24

${ }^{30}$ H.M. Atho Mudzhar, Membaca Gelombang Ijtihad (Yogyakarta: Titian Ilahi press, 1998), hlm. 93

${ }^{31}$ Yasraf Amir Piliang, "Sebuah Jagat Raya Maya: Imperialisme Fantasi dan Matinya Realitas", pengantar dalam Mark Slouka. Ruang Yang Hilang: Pandangan Humanis tentang Budaya Cyberspace Yang Merisaukan (Bandung: Mizan, 1991), hlm. 14
} 
Jika rekonstruksi pemikiran keagamaan, termasuk fikih, pada abad XX terfokus pada bagaimana agama mampu menyediakan dasar-dasar hubungan yang progresif antara agama dan modernitas, maka di abad XXI, temanya harus bergeser pada bagaimana agama memposisikan diri di era informasi.Fikih sebagai salah satu bagian ajaran Islam yang sangat akrab dengan kehidupan sehari-hari masyarakat tidak bisa tidak harus ikut serta dalam proyek reinterpretasi ajaranajarannya untuk menyesuaikan dengan situasi baru, nilai-nilai dan terminologi-terminologi baru era informasi. Menjelaskan situasi baru dengan cara lama hanya akan menjadikan fikih tampak sangat renta dan kadaluarsa di tengah perubahan yang sangat cepat.

Realitas sosial memiliki peran penting dalam pembentukan hukum Islam; fikih. Para imam madzhab seperti Hanafi, Maliki, Syafi'i dan Hambali dalam menginterpretasikan ayat ataupun hadits sangat kental dipengaruhi sosio-kultur yang dihadapinya saat itu. Imam Syafi'i mempunyai qaul qadim dan qaul jadid merupakan bukti sejarah, perubahan fikihnya dipengaruhi oleh kondisi sosio kultur yang dihadapinya. Dan hukum Islampun memberikan posisi yang penting bagi sosio-kultur dalam proses pengembangan dan perubahan fikih. Bahkan salah satu kaidah ushul fikih secara tegas menyebutkan perubahan hukum mengikuti perubahan kondisi waktu dan tempat. ${ }^{32}$ Oleh sebab itu, perubahan zaman akan membawa implikasi perubahan pandangan fikih yang sesuai kondisi zaman.

Upaya merumuskan fikih virtual ataupun digital adalah langkah awal dalam membawa fikih yang dapat menjawab tantangan jaman 50 tahun kedepan. Kata kunci dari fikih virtual ataupun digital adalah dekonstruksi terminologi satu majlis atau hadir dari pertemuan physicaly menjadi pertemuan physically atau virtually. Ketika terminologi ini dapat disepakati oleh ulama dan cendekiawan muslim, maka fikih akan menemukan ruang gerak barunya di era globalisasi. Namun, jika terminologi ini belum dapat disepakati, maka ia akan tetap bertahan dengan paradigma lamanya dan perlahan akan ditinggalkan oleh zaman.

Sebagai respon akhir terhadap era Globalisasi dan masa depan fikih, rekonstruksi bangunan fikih yang berkembang sekarang menjadi sebuah keharusan. Permasalahan yang terjadi dan yang akan dihadapi di era globalisasi berbasiskan media informasi dan tekhnologi yang sudah tidak dibatasi dan terbatas oleh ruang dan waktu. Jadi, disinilah perlu membangun epistimologi fikih yang mampu mengimbangi percepatan arus media informasi dan tekhnologi. Jika hal ini terabaikan, maka fikih akan selalu kaget ketika menjamurnya berbagai permasalahan aktual yang terjadi. Dan akan selalu tertinggal dan hanya bisa mengekor dibelakang, bukan sebagai bagian perubahan yang mewarnai era baru. Sebagai penutup, lahirnya fikih virtual atau digital sebagai bentuk upgrade teks-teks fikih adalah kemestian zaman dari perubahan zaman. Atau - meminjam bahasa Ibrahim Husain ${ }^{33}$ - ia akan menjadi kumpulan dokumentasi normanorma yang utopis tak bermakna.

\section{Kesimpulan}

Sebagai respon akhir terhadap era Globalisasi dan masa depan fikih, rekonstruksi bangunan fikih yang berkembang sekarang menjadi sebuah keharusan. Permasalahan yang terjadi dan yang akan dihadapi di era globalisasi berbasiskan media informasi dan tekhnologi yang sudah tidak dibatasi dan terbatas oleh ruang dan waktu. Jadi, disinilah perlu membangun epistimologi fikih yang mampu mengimbangi percepatan arus media informasi dan tekhnologi.

\footnotetext{
${ }^{32}$ Mukhtar Yahya dan Fatchurrahman, Dasar-dasar Pembinaan Hukum Fiqh Islam (Bandung: PT. Al Ma'arif, 1997), hlm. 550

${ }^{33}$ Ibrahim Hosen, "Jenis-jenis Hukum dalam Hukum Pidana Islam” dalam Jamal D. Rahman et.al. (eds), Wacana Baru Fikih Sosial (Bandung: Mizan, 1997), hlm. 101
} 
Jika hal ini terabaikan, maka fikih akan selalu kaget ketika menjamurnya berbagai permasalahan aktual yang terjadi. Dan akan selalu tertinggal dan hanya bisa mengekor dibelakang, bukan sebagai bagian perubahan yang mewarnai era baru. Sebagai penutup, lahirnya fikih virtual atau digital sebagai bentuk upgrade teks-teks fikih adalah kemestian zaman dari perubahan zaman.Upaya merumuskan fikih virtual ataupun digital adalah langkah awal dalam membawa fikih yang dapat menjawab tantangan jaman 50 tahun kedepan. Kata kunci dari fikih virtual ataupun digital adalah dekonstruksi terminologi satu majlis atau hadir dari pertemuan physicaly menjadi pertemuan physically atau virtually. Ketika terminologi ini dapat disepakati oleh ulama dan cendekiawan muslim, maka fikih akan menemukan ruang gerak barunya di era globalisasi. Namun, jika terminologi ini belum dapat disepakati, maka ia akan tetap bertahan dengan paradigma lamanya dan perlahan akan ditinggalkan oleh zaman. 


\section{Buku}

\section{DAFTAR PUSTAKA}

Abdullah (ed), Taufik, Agama dan Perubahan Sosial, Jakarta: Rajawali Press, 1983

Abu Zahrah., Muhammad, Muhadharat fi 'aqdin nikah wa Atsaruh, Kairo: Darul Fikri Arabi, 1971

Amru, Yusuf, Istri-Istri Rasulullah, Contoh dan Teladan, Jakarta: Gema Insani Press, 1997

Azizy, A. Qadri,Melawan Globalisasi Ajaran Islam; Reinterpretasi Ajaran Islam Yogyakarta: Pustaka Pelajar, 2004

Bin Muhammad, Husain, Al ifshah an aqdin nikah ala madzahibil arba'ah, Suria: Darul Qalam Arabi, 1995

Briggs, Assa dan Peter Burke, Sejarah Sosial Media dari Gutenberg sampai Internet, Penerjemah. A. Rahman Zainuddin, Jakarta: Yayasan Obor, 2006

Fakih,Mansour,Runtuhnya Teori Pembangunan dan Globalisasi,Yogyakarta: Pustaka Pelajar, 2006

Harari, Abdullah, Umdatur Ragib, t.tp: Darul Masyari', 2009

Hermanto, Agus, Larangan Perkawinan, Yogyakarta: Lintang Rasi Aksara Books, 2016

Hill, David T. dan Krishna Sen, The Internet in Indonesia's New Democracy, New York: Routledge, 2005

Ibnu Muhammad Syatha, I'anah Tholibin,Beirut: dar Fikri, t.th

Jamal D. Rahman et.al. (eds), Wacana Baru Fikih Sosial,Bandung: Mizan, 1997

Mudzhar, H.M. Atho,Membaca Gelombang Ijtihad,Yogyakarta: Titian Ilahi Press, 1998

Peter L. Berger, Langit Suci, Agama sebagai Realitas Sosial (The Sacred Canopy: Elements of a Sociological Theory at Religion, Jakarta : LP3ES, 1991

Pip Jones, Pengantar Teori-Teori Sosial, terj. Achmad Fedyani Saifuddin,Jakarta: Yayasan Obor Indonesia, 2010

Robertson, Roland,Globalization : Social Theory and Global Culture, London: Sage, 1992

Sabiq, Sayid, Fiqhus Sunnah, Beirut: Darul Fikri, 1983 
eL-Mashlahah, Vol.8, No.2, 2018

Shields, Rob, The Virtual, terj. Hera Oktaviani, Yogyakarta: Jalasutra, 2011

Shubh, Abd al-Madjid,Ushul al-Manahij al-Fiqhiyyat,Kairo: Dar al-Wafa, 1989

Slouka, Mark,Ruang Yang Hilang: Pandangan Humanis tentang Budaya Cyberspace Yang Merisaukan, Bandung: Mizan, 1991

Yahya, Mukhtar dan Fatchurrahman, Dasar-dasar Pembinaan Hukum Fiqh Islam,Bandung: PT. Al Ma’arif, 1997

Zuhaili., Zuhaili, Fiqh al-Islami wa Adilatuh, Beirut: Dar Fikri, 1985 